\title{
A Family Segregating Lethal Primary Coenzyme Q10 Deficiency Due to Two Novel COQ6 Variants
}

\begin{abstract}
Na Wang ${ }^{1 \dagger}$, Youmin Zheng ${ }^{2 \dagger}$, Lingzi Zhang ${ }^{2}$, Xiong Tian ${ }^{3}$, Yicheng Fang ${ }^{4}$, Ming Qi ${ }^{5,6,7}$, Juping $D u^{1}$, Shuaishuai Chen ${ }^{1}$, Shiyong Chen ${ }^{1}$, Jun $L^{1}{ }^{1}$, Bo Shen ${ }^{1 *}$ and Lizhen Wang ${ }^{2 *}$

${ }^{1}$ Department of Clinical Laboratory, Taizhou Hospital of Zhejiang Province Affiliated to Wenzhou Medical University, Linhai, China, ${ }^{2}$ Department of Pediatrics, Taizhou Hospital of Zhejiang Province Affiliated to Wenzhou Medical University, Linhai, China, ${ }^{3}$ Department of Public Research Platform, Taizhou Hospital of Zhejiang Province Affiliated to Wenzhou Medical University, Linhai, China, ${ }^{4}$ Department of Radiology, Taizhou Hospital of Zhejiang Province Affiliated to Wenzhou Medical University, Linhai, China, ${ }^{5}$ Sir Run Run Shaw Hospital Affiliated to Zhejiang University School of Medicine, Hangzhou, China, ${ }^{6}$ DIAN Diagnostics, Hangzhou, China, ${ }^{7}$ Department of Pathology and Laboratory Medicine, University of Rochester Medical Center, Rochester, NY,

United States
\end{abstract}

OPEN ACCESS

Edited by:

Huiwen Zhang,

Xinhua Hospital, China

Reviewed by:

Eva Trevisson,

University of Padua, Italy

Nadia Akawi,

United Arab Emirates University,

United Arab Emirates

*Correspondence:

Bo Shen

shenb@enzemed.com

Lizhen Wang

wanglz@enzemed.com

${ }^{t}$ These authors shared first authorship

Specialty section: This article was submitted to Genetics of Common and Rare

Diseases,

a section of the journal

Frontiers in Genetics

Received: 09 November 2021 Accepted: 06 December 2021

Published: 17 January 2022

Citation:

Wang $N$, Zheng $Y$, Zhang L, Tian $X$, Fang Y, Qi M, Du J, Chen S, Chen S,

Li J, Shen B and Wang L (2022) A

Family Segregating Lethal Primary Coenzyme Q10 Deficiency Due to Two

Novel COQ6 Variants.

Front. Genet. 12:811833.

doi: 10.3389/fgene.2021.811833
Primary coenzyme Q10 deficiency-6 (COQ10D6), as a rare autosomal recessive disease caused by COQ6 mutations, is characterized by progressive infantile-onset nephrotic syndrome resulting in end-stage renal failure and sensorineural hearing loss. Here, we report two Chinese siblings with COQ10D6 who primarily presented with severe metabolic acidosis, proteinuria, hypoalbuminemia, growth retardation, and muscle hypotonia and died in early infancy. Using whole-exome sequencing and Sanger sequencing, we identified two rare recessive nonsense mutations in the COQ6 gene segregating with disease in affected family members: c.249C > G (p.Tyr83Ter) and c.1381C > T (p.Gln461Ter), resulting in two truncated protein products. Both mutations are located in a highly conserved area and are predicted to be pathogenic. Indeed, the death of our patients in early infancy indicates the pathogenicity of the p.Tyr83Ter and p.GIn461Ter variants and highlights the significance of the two variants for COQ6 enzyme function, which is necessary for the biosynthesis of coenzyme Q10. In conclusion, we discovered a novel compound heterozygous pathogenic variant of the COQ6 gene as a cause of severe COQ10D6 in the two siblings. Based on the clinical history and genetic characteristics of the patients, our cases expand the genotypic spectrum of COQ10D6 and highlight the heterogeneity and severity of clinical features associated with COQ6 mutations. For patients with clinical manifestations suggestive of COQ10D6, early testing for COQ6 mutations is beneficial for disease diagnosis and therapeutic interventions as well as disease prevention in future generations.

Keywords: COQ6 mutation, nephrotic syndrome, primary coenzyme Q10 deficiency, genetics, infancy

\section{INTRODUCTION}

Nephrotic syndrome (NS) is a chronic kidney disease that involves massive proteinuria, hypoalbuminemia, hyperlipidemia, and edema. When occurring in the first year of life, NS is considered a life-threatening clinical condition with poor prognosis and high mortality if not treated in time (Noone et al., 2018). NS is generally classified as steroid-dependent nephrotic syndrome 
(SDNS), steroid-resistant nephrotic syndrome (SRNS), or steroid-sensitive nephrotic syndrome (SSNS) based on its response to steroid therapy (Greenbaum et al., 2012; Trautmann et al., 2017). SRNS is a common cause of endstage renal disease (ESRD) in children, affecting approximately $10-20 \%$ of all pediatric NS cases (Warejko et al., 2018; Park et al., 2020), and the renal biopsies of affected patients usually show focal segmental glomerulosclerosis (FSGS) (Lovric et al., 2016).

Recently, large cohort studies have shown that approximately $30 \%$ of childhood-onset SRNS cases are associated with genetic defects (Sadowski et al., 2015; Wang et al., 2017; Nagano et al., 2020). Different variants of the genes involved in coenzyme Q10 (CoQ10) biosynthesis may lead to a renal phenotype, either syndromic SRNS (PDSS2, COQ2, and COQ6) or isolated SRNS (COQ8B) (Cheong 2020). Primary CoQ10 deficiency-6 (COQ10D6, OMIM \# 614650) is an autosomal recessive disorder that manifests as severe progressive infantile-onset NS resulting in end-stage renal failure and sensorineural hearing loss (SNHL) due to homozygous or compound heterozygous mutations in the COQ6 gene located on chromosome 14q24.3, which encodes an evolutionarily conserved flavin-dependent monooxygenase required for CoQ10 biosynthesis. Heeringa et al. (Heeringa et al., 2011) first reported that 11 children from five families with COQ10D6 manifest as NS and SNHL, and some of these patients responded favorably to oral CoQ10 treatment. In addition, high-dose exogenous CoQ10 supplementation at early stages of the disease can ameliorate the neurological and renal symptoms (Heeringa et al., 2011; Quinzii et al., 2014; Stanczyk et al., 2018). Nevertheless, patients may not benefit from CoQ10 therapy when severe renal and neurological damage is established. Hence, an early and accurate diagnosis of COQ10D6 and simultaneous CoQ10 intervention are critical in improving prognosis.

In this study, we identified a novel compound heterozygous variant of the COQ6 gene in a nonconsanguineous Chinese family with two siblings presenting severe metabolic acidosis, proteinuria, hypoalbuminemia, growth retardation, and muscle hypotonia; the female proband also developed seizures. Genetic findings showed that both mutations, located in the Ubi-OHase domain of COQ6, are present in a region that is highly evolutionarily conserved across species. The mutations are predicted to be pathogenic, as confirmed by the death of our patients in early infancy. Collectively, our findings widen the spectrum of known COQ6 mutations and provide an expanded understanding of the clinical spectrum of the rare genetic disease COQ10D6.

\section{RESULTS}

\section{Clinical Presentations of the Family}

The two affected siblings were conceived by a healthy, nonconsanguineous couple who denied having hepatitis, tuberculosis, diabetes, allergic diseases, or a history of hereditary disease. The mother of the patients has a history of miscarriages. A summary of the molecular findings and clinical and biochemical characteristics of the two cases harboring COQ6 mutations is shown in Table 1 . The pedigree of the family and the confirmation of the COQ6 mutations are presented in Figure 1A.

\section{Patient 1}

The proband (III-3) was a Chinese girl born at full term via spontaneous vaginal delivery who weighed $3.1 \mathrm{~kg}$. According to her parents, the infant had not achieved the expected increases in height and body weight by the age of 3 months. At the age of 4 months and 28 days, she was sent to our hospital due to repeated convulsion for 5 days. Metabolic and hearing exams were normal. The blood gas analysis indicated compensatory metabolic acidosis with an elevated lactate level $(5.4 \mathrm{mmol} / \mathrm{L})$, a $\mathrm{pH}$ of 7.39, and a bicarbonate level of $13.4 \mathrm{mmol} / \mathrm{L}$. Biochemical assays revealed significantly decreased albumin $(23.7 \mathrm{~g} / \mathrm{L})$ and increased blood lipids (triglyceride (TG), $15.80 \mathrm{mmol} / \mathrm{L}$; total cholesterol (TC), $9.54 \mathrm{mmol} / \mathrm{L})$. A decline in immunity was also observed with $\operatorname{IgG}<0.75 \mathrm{~g} / \mathrm{L}, \operatorname{IgA}<0.01 \mathrm{~g} / \mathrm{L}$, and $\operatorname{IgM}$ $<0.20 \mathrm{~g} / \mathrm{L}$. The urine organic acid (UOA) analysis showed increased levels of lactate, 3-hydroxybutyric acid-2, pyruvic acid-OX-2, 4-hydroxy-phenyllactate-2, palmitic acid-1, and malic acid-3. A widening of the bilateral frontotemporal subarachnoid space was detected by enhanced computed tomography (CT) (Figure 2C), though her electroencephalogram (EEG) was normal. During hospitalization, the patient developed a seizure during which her hands were clenched; the seizure abated after half a minute. The girl was then transferred to a higherlevel hospital at the request of her parents. Magnetic resonance imaging (MRI) demonstrated a widening of the bilateral frontotemporal subarachnoid space (Figures 2D,E) and delayed myelination of white matter (Figure 2F), but long-term EEG showed no abnormality. Laboratory testing indicated a markedly elevated TC level of $9.79 \mathrm{mmol} / \mathrm{L}$, an IgG level of $0.1 \mathrm{~g} / \mathrm{L}$, a CD $19^{+}$B cell percentage of $14.7 \%$, a $\mathrm{CD}^{+}$ $\mathrm{T}$-cell percentage of $72.8 \%$, and a $\mathrm{CD} 4^{+} \mathrm{T}$-cell percentage of $50.3 \%$. The girl's parents declined further genetic testing, and she was discharged home the next day.

At the age of 5 months and 22 days, she was admitted again to the Department of Pediatrics of our hospital because of pneumonia and dyspnea. Physical examination indicated that she had growth retardation, with a height of $54 \mathrm{~cm}$ and body weight of $5.5 \mathrm{~kg}$, which were both below $-3 \mathrm{SD}$, and she was unable to raise her head steadily. Laboratory tests revealed hypoalbuminemia $(16 \mathrm{~g} / \mathrm{L})$, massive proteinuria $(3+$, total urine protein of 2,570 mg/24 h), edema, and elevated blood lipids (TG, $27.51 \mathrm{mmol} / \mathrm{L}$; TC, $13.77 \mathrm{mmol} / \mathrm{L}$ ), accompanied by metabolic acidosis and electrolyte disturbances including decreased $\mathrm{Na}^{+}$ $(119 \mathrm{mmol} / \mathrm{L})$ and elevated $\mathrm{K}^{+}(6.48 \mathrm{mmol} / \mathrm{L})$. After admission, the patient received anti-infection and symptomatic treatment including repeated albumin for protein supplementation and repeated acid correction. Given the proband's clinical symptoms and age of onset, NS was considered and a blood sample was then collected for genetic testing. Unfortunately, she had persistent metabolic acidosis, hyponatremia, and hypoalbuminemia. She continued to deteriorate and died of respiratory failure and heart failure at the age of 5 months and 26 days. 
TABLE 1 | Clinical characteristics and molecular findings in subjects with COQ6 mutations.

\begin{tabular}{|c|c|c|}
\hline & Proband (III-3) & $\begin{array}{l}\text { Sibling } \\
\text { of proband (III-2) }\end{array}$ \\
\hline COQ6 mutation & c. $249 \mathrm{C}>\mathrm{G} / \mathrm{c} .1381 \mathrm{C}>\mathrm{T}$ & c. $249 \mathrm{C}>\mathrm{G} / \mathrm{c} .1381 \mathrm{C}>\mathrm{T}$ \\
\hline Sex & Female & Male \\
\hline Pregnancy duration & Full term & Full term \\
\hline Type of delivery & Spontaneous vaginal delivery & Spontaneous vaginal delivery \\
\hline Age at presentation & 4 months +23 days & 3 months +22 days \\
\hline Birth Weight (kg) & 3.1 & 2.95 \\
\hline Birth length (cm) & 50 & 50 \\
\hline Feeding difficulties & - & - \\
\hline Respiratory distress & + & + \\
\hline Muscle hypotonia & + & + \\
\hline Seizure & + & - \\
\hline SNHL & - & - \\
\hline Edema & + & + \\
\hline Lactate (mmol/L) & 5.4 & 7.8 \\
\hline Proteinuria (mg/24 h) & 2,570 & $\mathrm{n} / \mathrm{a}$ \\
\hline Serum albumin(g/L) & 23.7 & 24.8 \\
\hline UOA & $\begin{array}{l}\text { Lactic acid-2, pyruvic acid-OX-2, 3-hydroxybutyric acid-2, palmitic acid-1, 4-hydroxy- } \\
\text { phenyllactate- } 2 \text {, malic acid-3 }\end{array}$ & $\mathrm{n} / \mathrm{a}$ \\
\hline Brain MRI or head CT & $\begin{array}{l}\text { Bifrontal widening frontotemporal of the subarachnoid space; delayed myelination of white } \\
\text { matter }\end{array}$ & $\begin{array}{l}\text { Bifrontal widening frontotemporal of the } \\
\text { subarachnoid space }\end{array}$ \\
\hline Age at death & 5 months +26 days & 4 months +13 days \\
\hline
\end{tabular}

Note: SNHL, sensorineural hearing loss; UOA, urine organic acid; MRI, magnetic resonance imaging; CT, computed tomography; n/a, not done or not available.

\section{Patient 2}

Patient III-2 was the brother of the proband. He was also born at full term via spontaneous vaginal delivery with a birth weight of $2.95 \mathrm{~kg}$. At the age of 3 months and 22 days, he was admitted to our hospital because of repeated abdominal distension for 3 months, along with dyspnea and cyanosis for half an hour. Upon hospitalization, physical examination was unremarkable except for dyspnea and poor growth and development, with a body weight of $4.5 \mathrm{~kg}$ and a height of $57 \mathrm{~cm}$, which were both below -2 SD. Laboratory examination showed cytomegalovirus infection, proteinuria $(2+)$, and occult blood $(2+)$. Blood gas analysis indicated compensatory respiratory alkalosis combined with metabolic acidosis with lactate at $7.8 \mathrm{mmol} / \mathrm{L}$. Moreover, he exhibited significant decreases in albumin $(24.8 \mathrm{~g} / \mathrm{L})$ and total protein $(40.7 \mathrm{~g} / \mathrm{L})$, along with an IgA level of $0.02 \mathrm{~g} / \mathrm{L}$ and increased lactic acid dehydrogenase (1123 U/L) and TG $(6.02 \mathrm{mmol} / \mathrm{L})$. Cardiac ultrasound revealed an atrial septal defect and pulmonary hypertension, and an electrocardiogram showed altered sinus rhythm $\mathrm{T}$ waves. The patient did not undergo a metabolic study, but his neonatal screening was normal. Regrettably, the boy remained in a critical condition after the application of symptomatic treatment.

The patient was then transferred to a higher-level hospital at the request of the parents. Chest and abdominal CT detected pulmonary inflammation and slightly enlarged liver, and abdominal ultrasound showed enlarged kidneys and poor liver texture. A widening of the bifrontal frontotemporal region of the subarachnoid space was indicated by the cranial CT exhibited (Figures 2A,B). Meanwhile, laboratory tests showed hypoalbuminemia, proteinuria $(2+)$, and edema as well as a decreased level of $\operatorname{IgG}(2.2 \mathrm{~g} / \mathrm{L})$. However, hypoalbuminemia was not ameliorated by symptomatic treatment, and he subsequently developed exacerbated lung infection and degressive transcutaneous oxygen saturation. Unfortunately, despite all treatments, he died due to pulmonary hemorrhage and respiratory failure at the age of 4 months and 13 days.

\section{Genetic Findings}

The proband (III-3) underwent genetic testing by WES. DNA samples from her parents and brother were tested to verify the variants using Sanger sequencing. As illustrated in Figure 1B, novel compound heterozygous mutations in the COQ6 gene (NM_182476.3:exon2:c.249C > G (p.Tyr83Ter) and exon12: c.1381C > T (p.Gln461Ter)) were found in the proband (III-3) and her brother (III-2), and Sanger sequencing validation identified their parents as heterozygous carriers for one of the mutations.

Figure 3A shows a schematic of the COQ6 gene containing the two identified variants, and the COQ6 protein with its functional domains was created. The first variant c.249C > G (p.Tyr83Ter) in exon 2 of 12 causes a change of amino acid 83 from tyrosine to a stop codon that results in a truncated protein or degradation and thus probably greatly affects the structure and function of the COQ6 enzyme. COQ6 variant c.1381C > T (p.Gln461Ter) occurs at the last exon and leads to a deletion of seven amino acids from the Ubi-OHases domain of COQ6. Evolutionarily, a tyrosine at position 83 and a glutamine at position 461 of the COQ6 enzyme are highly conserved among various species (Figure 3B). According to the gnomAD database, these variants are detected with no homozygosity at allele frequencies of 0.00003185 and 0.00003188 , demonstrating that they are not common benign variants in the populations included in the database. Furthermore, both variants are absent from ClinVar, and no previous patient with either variant has been described in 
A

I

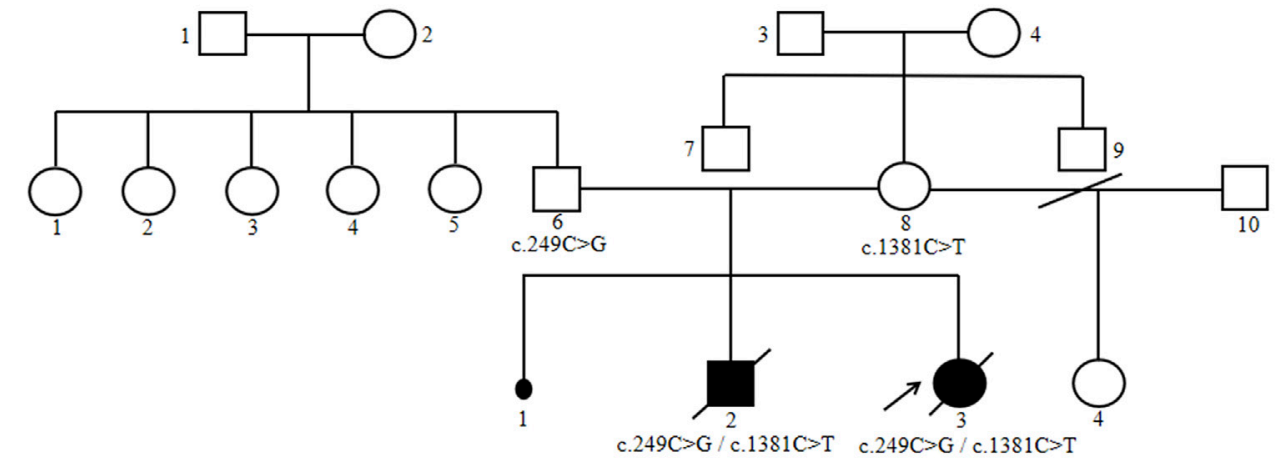

B
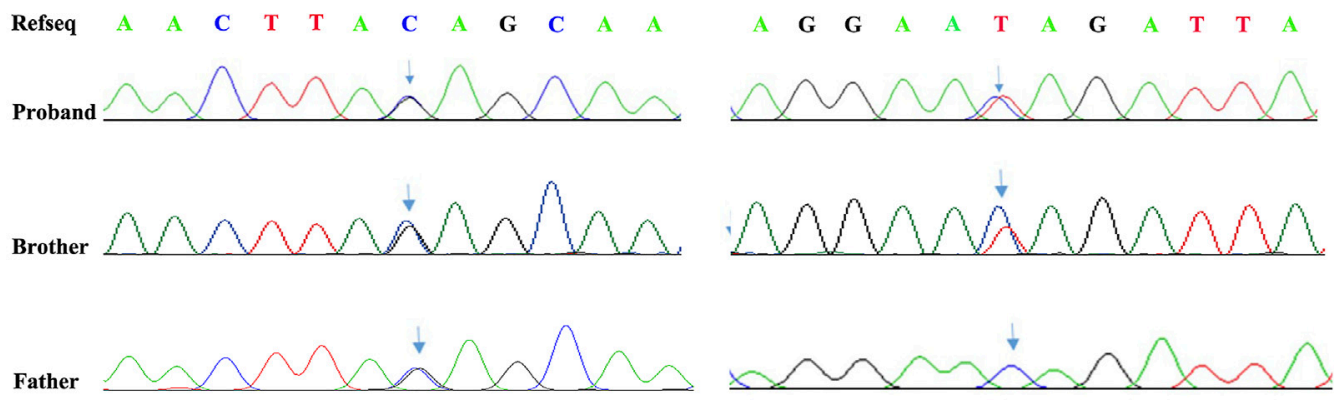

Mother
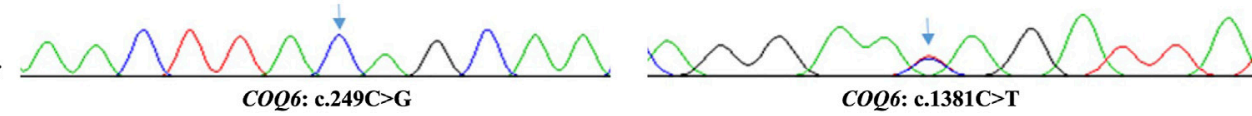

FIGURE 1 | Family pedigree and confirmation of the compound heterozygous variants of COQ6. (A) Pedigree shows the cosegregation of COQ6 mutations in the family. The patient pointed by the arrow indicates the proband. Black symbols indicate clinically affected members, and open symbols represent unaffected individuals.

(B) Validation of COQ6 variants in the family by Sanger sequencing, and the arrows represent sites of mutation.

the literature to date. Using MutationTaster, p.Tyr83Ter and p.Gln461Ter are predicted to be disease-causing variants and p.Tyr83Ter may lead to nonsense-mediated decay (NMD).

\section{DISCUSSION}

In the present study, we report two novel pathogenic COQ6 mutations: c.249C > G (p.Tyr83Ter) and c.1381C > T (p.Gln461Ter), which, in a compound heterozygous state, resulted in two siblings with clinical presentations of COQ10D6 characterized by renal involvements including hypoalbuminemia, proteinuria and edema, and extra-renal manifestations including growth retardation, muscle hypotonia, and/or seizures. Both mutations cosegregated with the disease, and the pathogenicity of the two COQ6 variants was confirmed by the clinical symptoms of our patients, the analysis of human genome variation databases, and in silico predictions.

CoQ10, also known as ubiquinone, is an important component of the mitochondrial electron transport chain; this compound exerts many effects, such as countering oxidation, regulating calcium homeostasis, improving mitochondrial function, and preventing cellular apoptosis (Hargreaves et al., 2020). To date, pathogenic mutations in 10 genes (PDSS1, PDSS2, COQ2, COQ4, COQ6, COQ7, COQ8A/ADCK3, COQ8B/ADCK4, and COQ9) involved in the biosynthesis of CoQ10 have been reported to cause primary CoQ10 deficiency, which has variable clinical symptoms ranging from fatal neonatal multisystem disorder to adult-onset encephalopathy or nephropathy (Desbats et al., 2015; Acosta et al., 2016). Several pathogenic mutations in the COQ6 gene are known to cause kidney dysfunction such as SRNS and extrarenal manifestations such as SHNL, seizures, growth retardation, and mild muscle weakness in the lower extremities (Heeringa et al., 2011; Cao et al., 2014; Park et al., 2017). The clinical manifestations in our cases and other reported patients are summarized in Table 2.

A mutation of the COQ6 gene was first reported as a cause of primary CoQ10 deficiency in the study of Heeringa et al. (2011) The authors reported that all affected patients $(n=11)$ presenting with SRNS and SNHL showed proteinuria with a median onset age of 1.2 years (range, $0.2-6.4$ years) and ESRD with a median onset age of 1.7 years (range, $0.4-9.3$ years); five cases also 

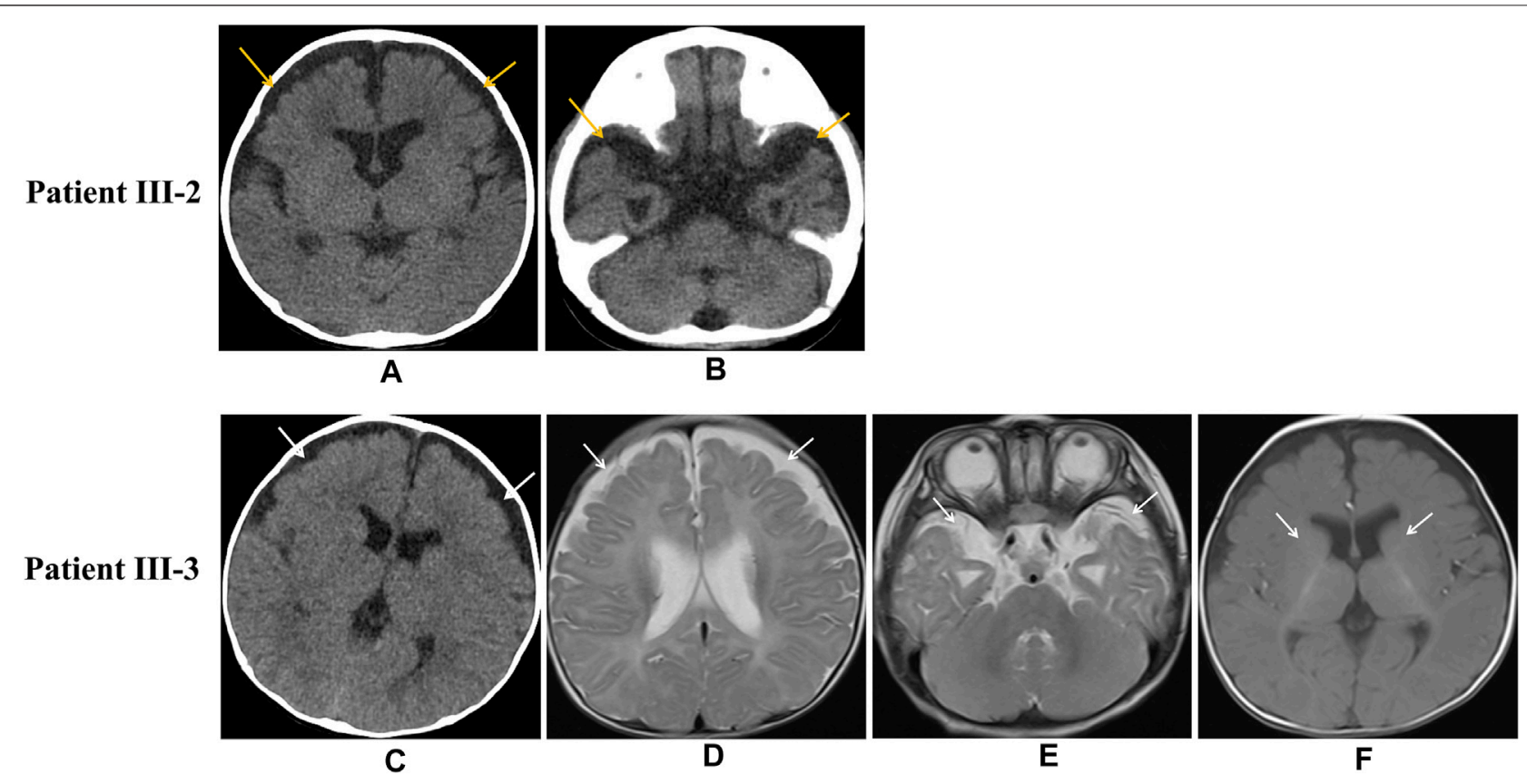

FIGURE 2 | Imaging of patient III-2 and patient III-3. Unenhanced head CT indicates widening of the bifrontal frontotemporal subarachnoid space in patient III-2 (Figures 2A,B) Unenhanced head CT of patient III-3 shows bifrontal widening frontotemporal of the subarachnoid space (Figure 2C), and axial MRI shows bifrontal widening frontotemporal of the subarachnoid space (Figures 2D,E) and delayed myelination of white matter (Figure 2F).

presented with extrarenal involvement such as white matter abnormalities, seizures, ataxia, and facial dysmorphism. Gigante et al. (2017) reported an 8-month-old Italian boy with SRNS that progressed to ESRD when he was 20 months old but with no extra-renal involvements; the pathogenicity of the COQ6 p.Pro261Leu allele was then confirmed by rescue experiments in yeast. Park et al. (2017) reported six unrelated Korean children with SRNS and hearing loss, and mild muscle weakness of the lower extremities and ocular manifestations including bilateral optic nerve atrophy and exotropia were observed in four patients. The patients developed SRNS with onset at a median onset of 29 (range, 15-47) months and ERSD with onset at a median onset of 45 (range, 17-73) months; five of the patients underwent kidney transplantation without FSGS recurrence. Of note, these above patients with COQ6 defects manifested SRNS during childhood, and all cases progressed to ERSD within 1-2 years of onset. Furthermore, some affected individuals received timely highdosage oral CoQ10 administration after COQ6 mutations were detected, and their renal function and psychomotor development have been improved (Cao et al., 2017; Stanczyk et al., 2018; Justine et al., 2020). Remarkably, patients may not benefit from CoQ10 therapy after severe renal and neurological damages occur. These observations suggest that once COQ10D6 is suspected clinically, immediate CoQ10 treatment and detection of COQ6 mutations would be helpful for the improvement of patient prognosis.

Notably, clinical heterogeneity has been observed in patients carrying the same COQ6 mutations (see Table 2). For example, a 7-year-old girl from Turkey showed only SRNS without other systemic symptoms due to a homozygous COQ6 mutation c.1058C > A (p.Ala353Asp), while her elder brother harboring the same COQ6 mutation exhibited normal renal functions without any neurological presentations and developed SNHL at 10 years old (Yuruk et al., 2020). Additionally, Heeringa et al. (Heeringa et al., 2011) reported six patients with the COQ6 variant c.763G > A (p.Gln255Arg) who all had SRNS with or without other extrarenal presentations such as SNHL, seizures, white matter abnormalities, and facial dysmorphism. Similarly, our patients with the same COQ6 mutations displayed variable clinical presentations, whereby the proband satisfying the diagnostic criteria of NS also showed growth retardation and muscle hypotonia in addition to seizures, which were not present in her older brother. Unlike most cases reported previously, our cases died in early infancy. Our findings highlight the clinical heterogeneity and the severity of the disorder caused by COQ6 defects.

Moreover, we uncovered two novel and rare pathogenic mutations in COQ6, which are essential for CoQ10 biosynthesis, and these findings contribute to the known genotypic spectrum of COQ10D6. To date, seven mutations in COQ6, including missense mutations, indels, and frameshifts, have been reported in the Human Gene Mutation Database (HGMD). To confirm the deleterious effect of p.Gln461Ter on COQ6 function, we evaluated the secondary structure of COQ6 with p.Gln461Ter mutation using PredictProtein and found that it affected the secondary structure and solvent to some extent (Figure 4A). The Gln461Ter led to a deletion of seven amino acids of the COQ6 C-terminus located on the surface of the active site (Doimo et al., 2014), which was confirmed to be functionally important by a recent study demonstrating that the deletion of 25 amino acids at the COQ6 C-terminus leads to impaired CoQ10 


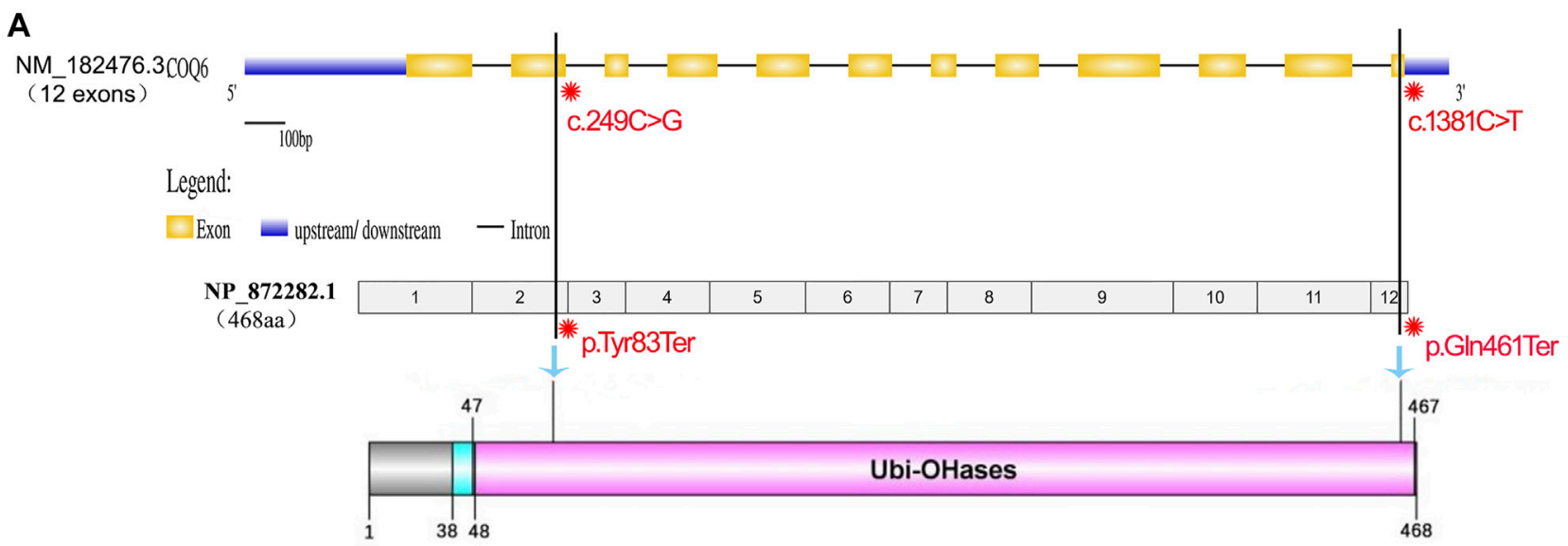

B

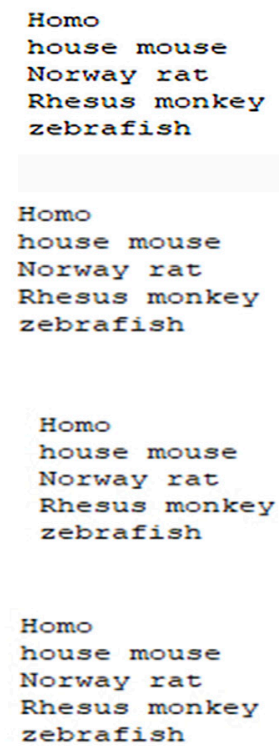

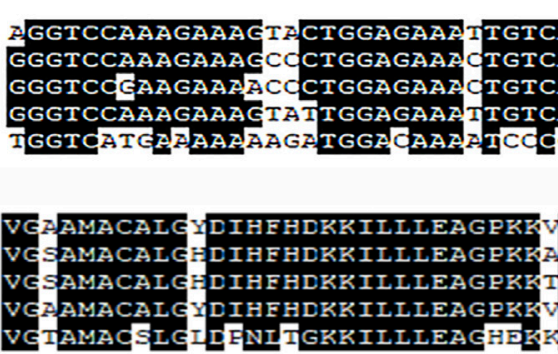

c. 249 C> G p.Tyr83Ter

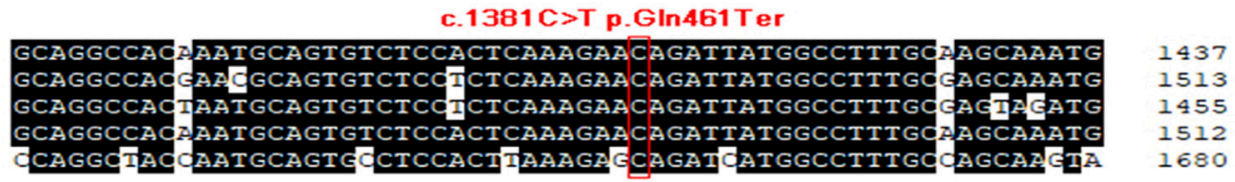

c. $1381 \mathrm{C}>\mathrm{T}$ p.GIn461 Ter

\begin{tabular}{|c|c|}
\hline & \\
\hline SVSHLTGYETERQRHNTALLAATDLLRRLYSTSAS & PLVLLRTWGLQATNAVSPIRECIMA \\
\hline LTGYETDRQRHNTALLAATDILKRLYSTST & PLVLLRTWGLQATNAVSPIKECIMA \\
\hline $\begin{array}{l}\text { SMSHLTGYETERQRHNTALLAATDLLKRLYSTSA } \\
\text { AMCHIIEFETERQRHNIRMHTIIDLMKRLYSSNT }\end{array}$ & $\begin{array}{l}\text { PLVLLRTWGLQATNAVSPLKEQI } \\
\text { PMVLLRTFGLQATNAVERIKEQI }\end{array}$ \\
\hline
\end{tabular}

FIGURE 3 | Schematic of the gene structure and domain structure of COQ6 protein and conservation analysis of the two nonsense mutations detected in the family. (A) The COQ6 gene containing 12 exons (yellow boxes) was exhibited using the UDSD online database, and the location of the two variants is tagged in the COQ6 exon region and its corresponding Ubi-OHases domain. (B) Comparative analysis of genome sequences or CDSs across species indicates that the two mutant sites are evolutionarily highly conserved.

synthesis (Acosta et al., 2019). These results suggest that the two novel COQ6 mutants identified in our study are likely both lossof-function variants; the p.Try81Ter causes NMD and p.Gln461Ter perturbs the active site and secondary structure of the COQ6 protein. In addition, COQ6 was found to correlate closely with COQ3, COQ4, COQ5, COQ7, and COQ9 in a PPI network (Figure 4B). Human PDSS2, COQ4, COQ6, and COQ7 could form a protein complex in human mitochondria, and the knockdown of COQ6 markedly resulted in reduced levels of COQ3; this, in turn, causes an obvious decrease of COQ7, which is crucial for maintaining the mitochondrial function (Yen et al., 2020). Furthermore, the decreased expression of the COQ6 protein was revealed to cause kidney damage by inducing mitochondrial dysfunction and apoptosis in podocytes (Song et al., 2018). Thus, we suspect that the candidate pathogenic variants (p.Tyr83Ter and p.Gln461Ter) may impede the interaction between COQ6 and other mitochondrial proteins in the CoQ complex, thus disrupting the pathway of CoQ10 biosynthesis and ultimately impairing renal function. This may be the reason for the more severe phenotype in the current cases.

However, the present study had some limitations. Due to premature mortality in infancy, we could not confirm our molecular finding through the detection of CoQ10 levels in skeletal muscle and the level of COQ6 protein in skin fibroblasts from patients. Although the pathogenicity of the two novel COQ6 variants identified in our study is explained by several findings, including the clinical phenotype of the two 
TABLE 2 | Genotypic and phenotypic characteristics of the detected COQ6 variants in the published literature and the present study.

\begin{tabular}{|c|c|c|c|c|c|c|c|c|}
\hline Origin & $\begin{array}{l}\text { Age at } \\
\text { onset } \\
\text { (year) }\end{array}$ & $\begin{array}{l}\text { Age at } \\
\text { ESRD } \\
\text { (year) }\end{array}$ & $\begin{array}{c}\text { COQ6 } \\
\text { mutations }\end{array}$ & Zygosity & $\begin{array}{c}\text { Renal } \\
\text { involvement }\end{array}$ & $\begin{array}{l}\text { Extra-renal } \\
\text { involvement }\end{array}$ & $\begin{array}{c}\text { Effect } \\
\text { of CoQ10 } \\
\text { and its } \\
\text { analogue } \\
\text { treatment }\end{array}$ & References \\
\hline China & 0.4 & No & $\begin{array}{l}\text { c. } 249 \mathrm{C}>\mathrm{G} \text { (p.Tyr83Ter) } \\
\text { c. } 1381 \mathrm{C}>\mathrm{T} \text { (p.Gln461Ter) }\end{array}$ & Heterozygous & NS & $\begin{array}{l}\text { Growth retardation, } \\
\text { seizures, muscle } \\
\text { hypotonia }\end{array}$ & ND & Current study \\
\hline China & 0.3 & No & $\begin{array}{l}\text { c. } 249 \mathrm{C}>\mathrm{G} \text { (p.Tyr83Ter) } \\
\text { c.1381C > T (p.Gln461Ter) }\end{array}$ & Heterozygous & Proteinuria & $\begin{array}{l}\text { Growth retardation, } \\
\text { muscle hypotonia }\end{array}$ & ND & Current study \\
\hline Turkey & 0.2 & NA & c.763G > A (p.Gln255Arg) & Homozygous & SRNS & $\begin{array}{l}\text { SNHL, bilateral } \\
\text { nephrolithiasis, growth } \\
\text { retardation }\end{array}$ & Recovery of kidney function & $\begin{array}{l}\text { Heeringa et al. } \\
\text { (2011) }\end{array}$ \\
\hline Turkey & 0.3 & 0.4 & c.763G > A (p.Gln255Arg) & Homozygous & SRNS & $\begin{array}{l}\text { SNHL, facial } \\
\text { dysmorphism }\end{array}$ & $\begin{array}{l}\text { SNHL substantially } \\
\text { improved }\end{array}$ & $\begin{array}{l}\text { Heeringa et al. } \\
\text { (2011) }\end{array}$ \\
\hline Turkey & 0.3 & 0.4 & c.763G > A (p.Gln255Arg) & Homozygous & SRNS & Seizures & ND & $\begin{array}{l}\text { Heeringa et al. } \\
\text { (2011) }\end{array}$ \\
\hline Lebanon & 0.3 & 1.7 & c.763G > A (p.Gln255Arg) & Homozygous & SRNS & SNHL & ND & $\begin{array}{l}\text { Heeringa et al. } \\
\text { (2011) }\end{array}$ \\
\hline Lebanon & $<1.0$ & 3.0 & c.763G > A (p.Gln255Arg) & Homozygous & SRNS & SNHL & ND & $\begin{array}{l}\text { Heeringa et al. } \\
\text { (2011) }\end{array}$ \\
\hline Lebanon & 1.2 & 1.4 & c.763G > A (p.Gln255Arg) & Homozygous & SRNS & SNHL, ataxia & ND & $\begin{array}{l}\text { Heeringa et al. } \\
(2011)\end{array}$ \\
\hline Lebanon & 6.4 & 9.3 & c.763G > A (p.Gln255Arg) & Homozygous & SRNS & $\mathrm{SNHL}$ & ND & $\begin{array}{l}\text { Heeringa et al. } \\
(2011)\end{array}$ \\
\hline Turkey & 2.5 & 3.4 & c.1058C > A (p.Ala353Asp) & Homozygous & SRNS & $\begin{array}{l}\text { SNHL, seizures, white } \\
\text { matter abnormalities }\end{array}$ & ND & $\begin{array}{l}\text { Heeringa et al. } \\
(2011)\end{array}$ \\
\hline Turkey & 6.0 & 6.5 & c.1058C > A (p.Ala353Asp) & Homozygous & SRNS & $\mathrm{SNHL}$ & ND & $\begin{array}{l}\text { Heeringa et al. } \\
\text { (2011) }\end{array}$ \\
\hline Turkey & 2.5 & NA & c. $1058 \mathrm{C}>$ A (p.Ala353Asp) & Homozygous & SRNS & SNHL & Remission of proteinuria & $\begin{array}{l}\text { Heeringa et al. } \\
(2011)\end{array}$ \\
\hline Turkey & 3.0 & NA & $\begin{array}{l}\text { c.1341G > A (p.Trp447Ter) } \\
\text { c.1383delG } \\
\text { (p.Gln461fsTer478) }\end{array}$ & Heterozygous & SRNS & SNHL & ND & $\begin{array}{l}\text { Heeringa et al. } \\
\text { (2011) }\end{array}$ \\
\hline European & 4.5 & NA & $\begin{array}{l}\text { c. } 1154 \text { A > C (p.Asp385Ala) } \\
\text { c.1235A > G (p.Tyr412Cys) }\end{array}$ & Heterozygous & SRNS & NA & ND & $\begin{array}{l}\text { Sadowski } \\
\text { et al. (2015) }\end{array}$ \\
\hline China & 0.8 & NA & c.1078C > T (p.R360W) & Homozygous & SRNS & $\begin{array}{l}\text { SNHL, growth } \\
\text { retardation, muscle } \\
\text { hypotonia }\end{array}$ & $\begin{array}{l}\text { Complete remission of NS; } \\
\text { improved psychomotor } \\
\text { development }\end{array}$ & $\begin{array}{l}\text { Cao et al. } \\
(2017)\end{array}$ \\
\hline Korea & 1.2 & 1.4 & $\begin{array}{l}\text { c.189_191delGAA } \\
\text { (p.Lys64del); c.782C > T } \\
\text { (p.Pro261Leu) }\end{array}$ & Heterozygous & SRNS & $\begin{array}{l}\text { SNHL, bilateral optic } \\
\text { nerve atrophy }\end{array}$ & NA & $\begin{array}{l}\text { Park et al. } \\
(2017)\end{array}$ \\
\hline Korea & 1.9 & 2.6 & $\begin{array}{l}\text { c.189_191delGAA } \\
\text { (p.Lys64del); c.686A > C } \\
\text { (p.Gln229Pro) }\end{array}$ & Heterozygous & SRNS & $\begin{array}{l}\text { SNHL, extropia with } \\
\text { nistagmus on both } \\
\text { eyes }\end{array}$ & NA & $\begin{array}{l}\text { Park et al. } \\
(2017)\end{array}$ \\
\hline Korea & 2.0 & 3.6 & $\begin{array}{l}\text { c.189_191delGAA } \\
\text { (p.Lys64del); c.782C > T } \\
\text { (p.Pro261Leu) }\end{array}$ & Heterozygous & SRNS & $\begin{array}{l}\text { SNHL, mild muscle } \\
\text { weakness in the lower } \\
\text { extremities }\end{array}$ & NA & $\begin{array}{l}\text { Park et al. } \\
(2017)\end{array}$ \\
\hline Korea & 2.6 & 4.6 & $\begin{array}{l}\text { c.189_191delGAA (p. } \\
\text { Lys64del); c.782C > T } \\
\text { (p.Pro261Leu) }\end{array}$ & Heterozygous & SRNS & SNHL & NA & $\begin{array}{l}\text { Park et al. } \\
(2017)\end{array}$ \\
\hline Korea & 3.8 & 6.1 & $\begin{array}{l}\text { c.189_191delGAA (p. } \\
\text { Lys64del); c.782C > T } \\
\text { (p.Pro261Leu) }\end{array}$ & Heterozygous & SRNS & $\begin{array}{l}\text { SNHL, mild muscle } \\
\text { weakness in the lower } \\
\text { extremities }\end{array}$ & NA & $\begin{array}{l}\text { Park et al. } \\
(2017)\end{array}$ \\
\hline Korea & 3.9 & 4.0 & $\begin{array}{l}\text { c.189_191delGAA ( } p \text {. } \\
\text { Lys64del); c.782C > T } \\
\text { (p.Pro261Leu) }\end{array}$ & Heterozygous & SRNS & SNHL & NA & $\begin{array}{l}\text { Park et al. } \\
(2017)\end{array}$ \\
\hline Italy & 0.6 & 1.7 & c.782C > T (p.Pro261Leu) & Homozygous & SRNS & None & $\begin{array}{l}\text { Delayed neurological } \\
\text { disease }\end{array}$ & $\begin{array}{l}\text { Gigante et al. } \\
(2017)\end{array}$ \\
\hline China & 16 & NA & c.41G > A (p.Try14Ter) & Homozygous & SRNS & None & ND & $\begin{array}{l}\text { Song et al. } \\
\text { (2018) }\end{array}$ \\
\hline China & 0.2 & NA & c. $1078 \mathrm{C}>\mathrm{T}$ (p.R360W) & Homozygous & $\begin{array}{l}\text { Congenital } \\
\text { NS }\end{array}$ & None & ND & Li et al. (2018) \\
\hline Poland & 2.0 & NA & $\begin{array}{l}\text { c.1078C > T (p. Arg360Trp); } \\
\text { c.804delC } \\
\text { (p.Leu269TrpfsTer13) }\end{array}$ & Heterozygous & SRNS & None & Complete remission of NS & $\begin{array}{l}\text { Stanczyk et al. } \\
(2018)\end{array}$ \\
\hline
\end{tabular}


TABLE 2 | (Continued) Genotypic and phenotypic characteristics of the detected COQ6 variants in the published literature and the present study.

\begin{tabular}{|c|c|c|c|c|c|c|c|c|}
\hline Origin & $\begin{array}{c}\text { Age at } \\
\text { onset } \\
\text { (year) }\end{array}$ & $\begin{array}{c}\text { Age at } \\
\text { ESRD } \\
\text { (year) }\end{array}$ & $\begin{array}{c}\text { COQ6 } \\
\text { mutations }\end{array}$ & Zygosity & $\begin{array}{c}\text { Renal } \\
\text { involvement }\end{array}$ & $\begin{array}{l}\text { Extra-renal } \\
\text { involvement }\end{array}$ & $\begin{array}{l}\text { Effect } \\
\text { of CoQ10 } \\
\text { and its } \\
\text { analogue } \\
\text { treatment }\end{array}$ & References \\
\hline Japan & 0.8 & NA & c.782C > T (p.Pro261Leu) & Heterozygous & SRNS & None & $\begin{array}{l}\text { Complete remission of } \\
\text { proteinuria }\end{array}$ & $\begin{array}{l}\text { Nakanishi } \\
\text { et al. (2019) }\end{array}$ \\
\hline Turkey & 7.0 & 8.0 & c.1058C > A (p.Ala353Asp) & Homozygous & SRNS & None & $\begin{array}{l}\text { Kidney function improved } \\
\text { with No complications } \\
\text { related with the renal } \\
\text { transplantation }\end{array}$ & $\begin{array}{l}\text { Yuruk et al. } \\
(2020)\end{array}$ \\
\hline Turkey & 10 & NA & c.1058C > A (p.Ala353Asp) & Homozygous & None & $\mathrm{SNHL}$ & $\begin{array}{l}\text { Delayed renal or } \\
\text { neurological disease }\end{array}$ & $\begin{array}{l}\text { Yuruk et al. } \\
(2020)\end{array}$ \\
\hline Turkey & NA & 5.0 & c.1058C > A (p.Ala353Asp) & Homozygous & SRNS & SNHL, optic atrophy & Visual acuity improved & $\begin{array}{l}\text { Justine et al. } \\
\text { (2020) }\end{array}$ \\
\hline Turkey & 4.0 & NA & c.1058C > A (p.Ala353Asp) & Homozygous & SRNS & SNHL & $\begin{array}{l}\text { Remission of proteinuria; } \\
\text { unchanged hearing loss }\end{array}$ & $\begin{array}{l}\text { Justine et al. } \\
\text { (2020) }\end{array}$ \\
\hline
\end{tabular}

Note: ESRD, end-stage renal disease; NS, nephrotic syndrome; SNHL, sensorineural hearing loss; SRNS, steroid-resistant nephrotic syndrome; ND, not done; NA, not available.

A

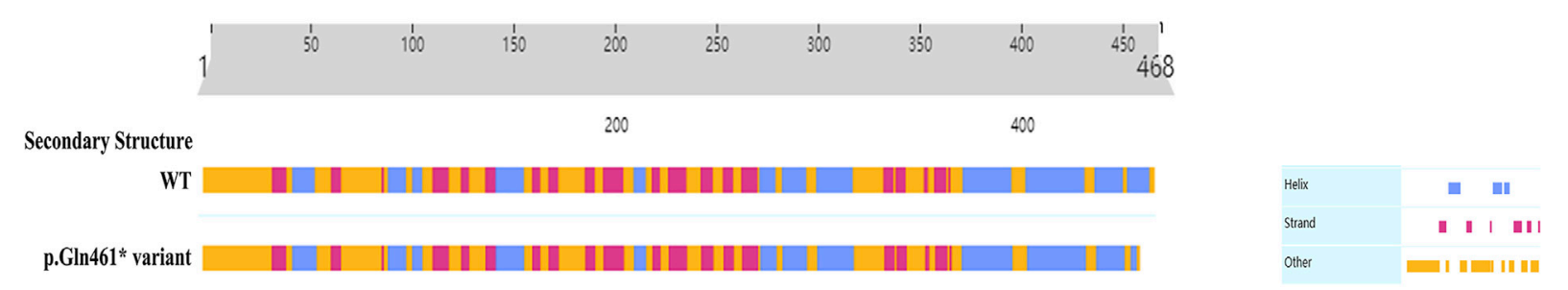

Sovlent Accessibility

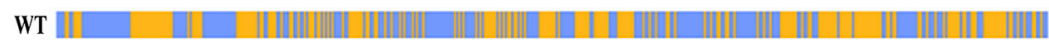

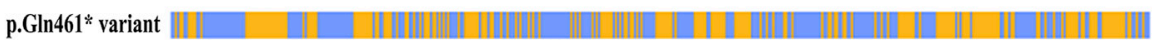

\begin{tabular}{|c|c|}
\hline Exposed & 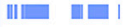 \\
\hline Buried & 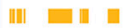 \\
\hline
\end{tabular}

B

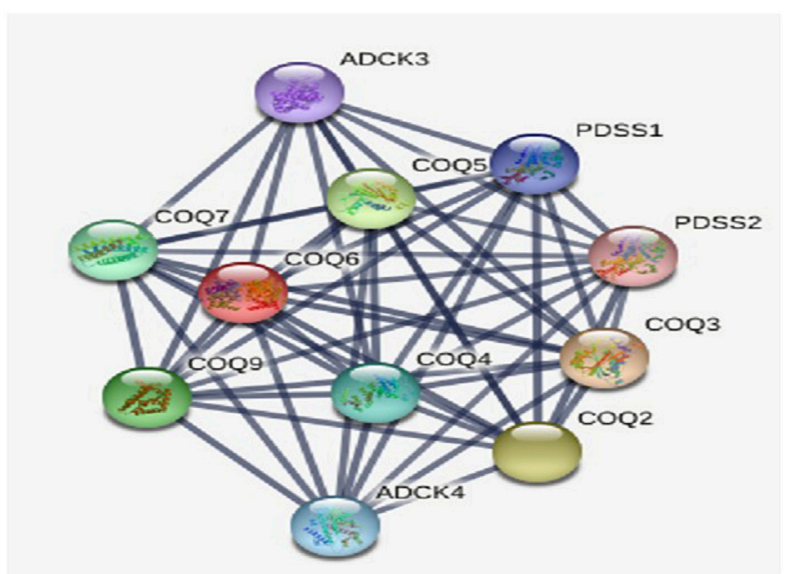

1. Biogical functions

- Ubiquinone biosynthenic process

- Glycerol metabolic process

- Isoprenoid biosynthetic process

- Oxidareducion coenzyme metabolic process

- Coenzyme biosynthenic process

2. Domain functions

- UbiB domain

UbiB domain, $\mathrm{ADCK}-3$ like

FIGURE 4 | Secondary structure analysis of the COQ6 protein and STRING network analysis. (A) Secondary structure and solvent accessibility of wild-type COQ6 and the protein with the candidate variant ( $p . G \ln 461 \mathrm{Ter}$ ) were analyzed using the PredictProtein online database. (B) The functional association of the COQ6 with other proteins involved in the pathway of CoQ10 biosynthesis was predicted by STRING network analysis (STRING v11.0, https://stringdb.org/). 
probands overlapping with patients harboring COQ6 mutations as previously reported, the segregation with the disease, and bioinformatics predictions, in-depth studies are still needed to further determine the impact of the two candidate mutations on COQ6 gene expression and function.

In conclusion, our study provides the first report of a novel compound heterozygous pathogenic variant of the COQ6 gene in a Chinese family with severe COQ10D6. Our cases widen the genotypic spectrum of COQ10D6 and highlight the heterogeneity and severity of clinical features associated with COQ6 mutations. An early diagnosis of COQ6 pathogenic mutations in such cases with clinical presentations suggestive of COQ10D6 will facilitate disease diagnosis and therapeutic interventions as well as disease prevention in future generations.

\section{MATERIALS AND METHODS}

\section{Ethics Statement}

The study was performed in accordance with the Declaration of Helsinki and approved by the Ethics Committee of Taizhou Hospital of Zhejiang Province Affiliated to Wenzhou Medical University. Informed consent was obtained from the family before gene testing.

\section{Subjects}

We collected blood samples and pedigrees after obtaining informed consent from the family. The two affected siblings were diagnosed with infantile NS by pediatric nephrologists based on the age of presentation (4-12 months) and the diagnostic criteria of NS, including serum albumin $\leq 25 \mathrm{~g} / \mathrm{L}$, proteinuria $(24 \mathrm{~h}$ urine greater than $50 \mathrm{mg} / \mathrm{kg} /$ day $)$, and hyperlipidemia (elevated cholesterol and/or triglycerides) (Lombel et al., 2013); (Wang and Greenbaum 2019). The clinical and molecular biological characteristics of the affected individuals were analyzed retrospectively.

\section{Genetic Testing}

Genomic deoxyribonucleic acid was isolated from the patient's whole blood, and exome sequencing was conducted using an Illumina NovaSeq 6000 sequencing system with 150 bp pairedend reads at an average $100 \times$ sequencing depth to cover the maximum genomic variations. The DNA sequence was aligned to the UCSC hg19/GRCh37 reference sequence. Variant calls and annotation were performed with a pipeline based on the Burrows-Wheeler aligner, in-house software, the Genome Aggregation Database (gnomAD), ClinVar, and custom annotation scripts. Thereafter, Sanger sequencing analysis was performed for variant confirmation and segregation using target sequence-specific primers on an ABI 3730xl sequencer and analyzed using Sequencing Analysis Software v5.2 (Applied Biosystems) and SeqMan (DNASTAR) according to the manufacturer's instructions.

\section{In Silico Analysis}

For the evolutionary conservation analysis of COQ6 candidate variants, the alignment of gene sequences and complete coding sequences from different species were conducted using DNAMAN, including human (NP_872282.1), rhesus monkey (XP_014999576.2), house mouse (NP_766170.2), Norway rat (NP_001011 983.1), and zebrafish (NP_001038869.1). Next, the pathogenicity of the variants was predicted by using MutationTaster, and the possible influence of the detected variants on the structure and function of the COQ6 protein was evaluated by PredictProtein. The diagram of the functional protein association network was depicted based on the STRING (https://string-db.org/) database, which was used to predict protein-protein interactions.

\section{DATA AVAILABILITY STATEMENT}

The datasets for this article are not publicly available due to concerns regarding participant/patient anonymity. Requests to access the datasets should be directed to the corresponding authors.

\section{ETHICS STATEMENT}

The studies involving human participants were reviewed and approved by The Ethics Committee of Taizhou Hospital of Zhejiang Province affiliated with Wenzhou Medical University. Written informed consent to participate in this study was provided by the participants' legal guardian/next of kin. Written informed consent was obtained from the individual(s), and minor(s)' legal guardian/next of kin, for the publication of any potentially identifiable images or data included in this article.

\section{AUTHOR CONTRIBUTIONS}

NW conceived of the study, analyzed the data and wrote the manuscript. YZ provided the clinical samples. YZ and LZ participated in the clinical data collection and clinical evaluations. XT conducted the bioinformatics analysis. FC interpreted the brain MRI and head CT of the patients. MQ, JD, and SC performed the genetics analysis. SC and JL conducted the biochemical analysis. BS and LW critically commented and revised the manuscript. All authors have read and approved the final version of the manuscript.

\section{ACKNOWLEDGMENTS}

We would like to thank the patients and their family members for participating in our study. We also thank Dian Diagnostics for their excellent technical assistance. Finally, we sincerely thank Children's Hospital of Fudan University and The Children's Hospital, Zhejiang University School of Medicine for providing patient imaging data. 


\section{REFERENCES}

Acosta Lopez, M. J., Trevisson, E., Canton, M., Vazquez-Fonseca, L., Morbidoni, V., Baschiera, E., et al. (2019). Vanillic Acid Restores Coenzyme Q Biosynthesis and ATP Production in Human Cells LackingCOQ6. Oxidative Med. Cell Longevity 2019, 1-11. doi:10.1155/2019/3904905

Acosta, M. J., Vazquez Fonseca, L., Desbats, M. A., Cerqua, C., Zordan, R., Trevisson, E., et al. (2016). Coenzyme Q Biosynthesis in Health and Disease. Biochim. Biophys. Acta (Bba) - Bioenerg. 1857 (8), 1079-1085. doi:10.1016/j.bbabio.2016.03.036

Cao, Q., Li, G. M., Xu, H., Shen, Q., Sun, L., Fang, X. Y., et al. (2017). Coenzyme Q(10) Treatment for One Child with COQ6 Gene Mutation Induced Nephrotic Syndrome and Literature Review. Zhonghua Er Ke Za Zhi 55 (2), 135-138. doi:10.3760/cma.j.issn.0578-1310.2017.02.016

Cheong, H. I. (2020). Genetic Tests in Children with Steroid-Resistant Nephrotic Syndrome. Kidney Res. Clin. Pract. 39 (1), 7-16. doi:10.23876/j.krcp.20.001

Desbats, M. A., Lunardi, G., Doimo, M., Trevisson, E., and Salviati, L. (2015). Genetic Bases and Clinical Manifestations of Coenzyme Q10 (CoQ10) Deficiency. J. Inherit. Metab. Dis. 38 (1), 145-156. doi:10.1007/s10545-014-9749-9

Doimo, M., Trevisson, E., Airik, R., Bergdoll, M., Santos-Ocaña, C., Hildebrandt, F., et al. (2014). Effect of Vanillic Acid on COQ6 Mutants Identified in Patients with Coenzyme Q10 Deficiency. Biochim. Biophys. Acta (Bba) - Mol. Basis Dis. 1842 (1), 1-6. doi:10.1016/j.bbadis.2013.10.007

Gigante, M., Diella, S., Santangelo, L., Trevisson, E., Acosta, M. J., Amatruda, M., et al. (2017). Further Phenotypic Heterogeneity of CoQ10 Deficiency Associated with Steroid Resistant Nephrotic Syndrome and Novel COQ2 and COQ6 Variants. Clin. Genet. 92 (2), 224-226. doi:10.1111/cge.12960

Greenbaum, L. A., Benndorf, R., and Smoyer, W. E. (2012). Childhood Nephrotic Syndrome-Current and Future Therapies. Nat. Rev. Nephrol. 8 (8), 445-458. doi:10.1038/nrneph.2012.115

Hargreaves, I., Heaton, R. A., and Mantle, D. (2020). Disorders of Human Coenzyme Q10 Metabolism: An Overview. Ijms 21 (18), 6695. doi:10.3390/ijms21186695

Heeringa, S. F., Chernin, G., Chaki, M., Zhou, W., Sloan, A. J., Ji, Z., et al. (2011). COQ6 Mutations in Human Patients Produce Nephrotic Syndrome with Sensorineural Deafness. J. Clin. Invest. 121 (5), 2013-2024. doi:10.1172/JCI45693

Justine Perrin, R., Rousset-Rouvière, C., Garaix, F., Cano, A., Conrath, J., Boyer, O., et al. (2020). COQ6 Mutation in Patients with Nephrotic Syndrome, Sensorineural Deafness, and Optic Atrophy. JIMD Rep. 54 (1), 37-44. doi: $10.1002 /$ jmd 2.12068

Li, G.-m., Cao, Q., Shen, Q., Sun, L., Zhai, Y.-h., Liu, H.-m., et al. (2018). Gene Mutation Analysis in 12 Chinese Children with Congenital Nephrotic Syndrome. BMC Nephrol. 19 (1), 382. doi:10.1186/s12882-018-1184-y

Lombel, R. M., Gipson, D. S., and Hodson, E. M. (2013). Treatment of SteroidSensitive Nephrotic Syndrome: New Guidelines from KDIGO. Pediatr. Nephrol. 28 (3), 415-426. doi:10.1007/s00467-012-2310-x

Lovric, S., Ashraf, S., Tan, W., and Hildebrandt, F. (2016). Genetic Testing in Steroid-Resistant Nephrotic Syndrome: When and How? Nephrol. Dial. Transpl. 31 (11), 1802-1813. doi:10.1093/ndt/gfv355

Nagano, C., Yamamura, T., Horinouchi, T., Aoto, Y., Ishiko, S., Sakakibara, N., et al. (2020). Comprehensive Genetic Diagnosis of Japanese Patients with Severe Proteinuria. Sci. Rep. 10 (1), 270. doi:10.1038/s41598-019-57149-5

Nakanishi, K., Okamoto, T., Nozu, K., Hara, S., Sato, Y., Hayashi, A., et al. (2019). Pair Analysis and Custom Array CGH Can Detect a Small Copy Number Variation in COQ6 Gene. Clin. Exp. Nephrol. 23 (5), 669-675. doi:10.1007/s10157-018-1682-z

Noone, D. G., Iijima, K., and Parekh, R. (2018). Idiopathic Nephrotic Syndrome in Children. The Lancet 392 (10141), 61-74. doi:10.1016/S0140-6736(18)30536-1

Park, E., Ahn, Y. H., Kang, H. G., Yoo, K. H., Won, N. H., Lee, K. B., et al. (2017). COQ6 Mutations in Children with Steroid-Resistant Focal Segmental Glomerulosclerosis and Sensorineural Hearing Loss. Am. J. Kidney Dis. 70 (1), 139-144. doi:10.1053/j.ajkd.2016.10.040
Park, E., Lee, C., Kim, N. K. D., Ahn, Y. H., Park, Y. S., Lee, J. H., et al. (2020). Genetic Study in Korean Pediatric Patients with Steroid-Resistant Nephrotic Syndrome or Focal Segmental Glomerulosclerosis. Jcm 9 (6), 2013. doi:10.3390/ jcm9062013

Quinzii, C. M., Emmanuele, V., and Hirano, M. (2014). Clinical Presentations of Coenzyme Q10 Deficiency Syndrome. Mol. Syndromol 5 (3-4), 141-146. doi:10.1159/000360490

Sadowski, C. E., Lovric, S., Ashraf, S., Pabst, W. L., Gee, H. Y., Kohl, S., et al. (2015). A Single-Gene Cause in $29.5 \%$ of Cases of Steroid-Resistant Nephrotic Syndrome. J. Am. Soc. Nephrol. 26 (6), 1279-1289. doi:10.1681/ ASN.2014050489

Song, C.-C., Hong, Q., Geng, X.-D., Wang, X., Wang, S.-Q., Cui, S.-Y., et al. (2018). New Mutation of Coenzyme Q10 Monooxygenase 6 Causing Podocyte Injury in a Focal Segmental Glomerulosclerosis Patient. Chin. Med. J. (Engl). 131 (22), 2666-2675. doi:10.4103/0366-6999.245158

Stańczyk, M., Bałasz-Chmielewska, I., Lipska-Ziętkiewicz, B., and Tkaczyk, M. (2018). CoQ10-related Sustained Remission of Proteinuria in a Child with COQ6 Glomerulopathy-A Case Report. Pediatr. Nephrol. 33 (12), 2383-2387. doi:10.1007/s00467-018-4083-3

Trautmann, A., Schnaidt, S., Lipska-Ziętkiewicz, B. S., Bodria, M., Ozaltin, F., Emma, F., et al. (2017). Long-Term Outcome of Steroid-Resistant Nephrotic Syndrome in Children. Jasn 28 (10), 3055-3065. doi:10.1681/ ASN.2016101121

Wang, C.-s., and Greenbaum, L. A. (2019). Nephrotic Syndrome. Pediatr. Clin. North America 66 (1), 73-85. doi:10.1016/j.pcl.2018.08.006

Wang, F., Zhang, Y., Mao, J., Yu, Z., Yi, Z., Yu, L., et al. (2017). Spectrum of Mutations in Chinese Children with Steroid-Resistant Nephrotic Syndrome. Pediatr. Nephrol. 32 (7), 1181-1192. doi:10.1007/s00467-0173590-y

Warejko, J. K., Tan, W., Daga, A., Schapiro, D., Lawson, J. A., Shril, S., et al. (2018). Whole Exome Sequencing of Patients with Steroid-Resistant Nephrotic Syndrome. Cjasn 13 (1), 53-62. doi:10.2215/CJN.04120417

Yen, H.-C., Yeh, W.-Y., Lee, S.-H., Feng, Y.-H., and Yang, S.-L. (2020). Characterization of Human Mitochondrial PDSS and COQ Proteins and Their Roles in Maintaining Coenzyme Q10 Levels and Each Other's Stability. Biochim. Biophys. Acta (Bba) - Bioenerg. 1861 (7), 148192. doi:10.1016/j.bbabio.2020.148192

Yuruk Yildirim, Z., Toksoy, G., Uyguner, O., Nayir, A., Yavuz, S., Altunoglu, U., et al. (2020). Primary Coenzyme Q10 Deficiency-6 (COQ10D6): Two Siblings with Variable Expressivity of the Renal Phenotype. Eur. J. Med. Genet. 63 (1), 103621. doi:10.1016/j.ejmg.2019.01.011

Conflict of Interest: Author MQ is employed by DIAN Diagnostics.

The remaining authors declare that the research was conducted in the absence of any commercial or financial relationships that could be construed as a potential conflict of interest.

Publisher's Note: All claims expressed in this article are solely those of the authors and do not necessarily represent those of their affiliated organizations, or those of the publisher, the editors and the reviewers. Any product that may be evaluated in this article, or claim that may be made by its manufacturer, is not guaranteed or endorsed by the publisher.

Copyright $\odot 2022$ Wang, Zheng, Zhang, Tian, Fang, Qi, Du, Chen, Chen, Li, Shen and Wang. This is an open-access article distributed under the terms of the Creative Commons Attribution License (CC BY). The use, distribution or reproduction in other forums is permitted, provided the original author(s) and the copyright owner(s) are credited and that the original publication in this journal is cited, in accordance with accepted academic practice. No use, distribution or reproduction is permitted which does not comply with these terms. 